\title{
STUDY DEMANDS, STUDY RESOURCES AND THE ROLE OF PERSONALITY CHARACTERISTICS IN PREDICTING THE ENGAGEMENT OF FIRST-YEAR UNIVERSITY STUDENTS
}

\author{
J. R. Cilliers* \\ e-mail: cilliers.jeanie@gmail.com

\section{K. Mostert*} \\ e-mail: Karina.Mostert@nwu.ac.za \\ *WorkWell Research Unit \\ Faculty of Economic and Management Sciences \\ North-West University (Potchefstroom Campus) \\ Potchefstroom, South Africa
}

\section{J. A. Nel}

Department of Human Resource Management

University of Pretoria

Pretoria, South Africa

e-mail: alewyn.nel@up.ac.za

\section{ABSTRACT}

The objective of this study was to investigate significant predictors of student engagement, including study demands, study resources and personality characteristics. First-year university students $(N=512)$ participated in the study. The findings showed significant relationships between pace and amount of work and cognitive demands with student engagement, although only cognitive demands was a significant predictor of student engagement in the regression analysis. Even though all the study resources were significantly related to student engagement, the only significant predictors in the regression analysis were support from lecturers and opportunities for growth and development. When personality dimensions were included in the fourth step of the regression analysis, only opportunities for growth and development and achievement orientation (a facet of conscientiousness) were significant predictors of student engagement. Demands explained 6 per cent of the variance in study engagement, resources 17 per cent and personality characteristics and additional 11 per cent.

Keywords: Student engagement, study demands, study resources, personality characteristics, Job Demands-Resources theory, first-year university students

\section{INTRODUCTION}


Student engagement is an important topic for universities. Student engagement is strongly related to academic performance and student success (Asghar 2014; Hirschfield and Gasper 2011; Salanova and Schaufeli 2008). Highly engaged students are intrinsically motivated, are more invested in their academics, have higher rates of class attendance and have healthy lives by also participating in non-academic activities (Salanova et al. 2009). Students who are engaged are usually more successful in life, cope better with the challenges of the new work environment and are more successful in dealing with a volatile and uncertain global economy; they enjoy learning, are passionate about their academics and are curious and dedicated to their studies (Asghar 2014; Salanova et al. 2009; Siu, Bakker and Jiang 2014). Students who are engaged in their studies are an asset to universities and a key factor to prevent dropout and promote retention (Pohl 2013). Information on predictors of student engagement can be valuable for universities in several ways, including enhancing quality education and providing students with the necessary support systems (Coates 2005; Kuh 2009).

Due to the importance and growing interest in the concept of student engagement, more studies draw on organisational studies and theoretical frameworks or theories of work engagement, including the Job Demands-Resources (hereafter: JD-R) theory (Bakker, Vergel and Kuntze 2015; Llorens et al. 2006; Salmela-Aro and Upadyaya 2014). Building on the findings of previous studies (Parsons and Taylor 2011; Upadyaya and Salmela-Aro 2013), the current study aims to examine how study demands and study resources that firstyear South African university students experience impact their engagement levels and what the contribution of personality characteristics are.

Including personality of students is important since previous research showed that personality has an effect on engagement and academic effort (Ongore 2014; Strauser, O’Sullivan and Wong 2012). In South Africa, psychometric and psychological testing was for a long time viewed as unfair and discriminatory (Paterson and Uys 2005). This was mainly because questionnaires from Western origin were used without taking into account cultural differences (Fetvadjiev et al. 2015). As a result, there was a need for a valid, reliable and equivalent personality questionnaire for all 11 official language groups in the South African context (Fetvadjiev et al. 2015; Foxcroft and Roodt 2013). As a result, an indigenous inventory was developed known as The South African Personality Inventory (hereafter: SAPI) (Nel et al. 2012; Valchev et al. 2011). However, to date, the dimensions of the SAPI were not yet applied as predictors of engagement amongst university students.

The aim of the present study is to investigate the predictive value of study demands, 
study resources and personality characteristics as measured by the SAPI in a sample of first-year university students in a South African university.

\section{LITERATURE REVIEW}

\section{Student engagement, study demands and study resources}

Work engagement of employees has often been studied in the framework of the JD-R model with the ultimate goal of optimising employee performance (Bakker and Demerouti 2007; Bakker, Van Veldhoven and Xanthopoulou 2010). One of the basic assumptions of the JD-R model is that various work-related aspects and risk factors associated with work can be divided into two general categories: job demands and job resources (Demerouti et al. 2001; Xanthopoulou et al. 2007; Van den Broeck et al. 2008). Job demands are defined as those physical, psychological, social or organisational aspects of a job that require continuous physical and/or psychological effort from an individual, and hence imply certain psychological and physical costs (Bakker and Demerouti 2007; Bakker, Demerouti and Schaufeli 2003; Bakker, Van Veldhoven and Xanthopoulou 2010). Job resources refer to those physical, psychological, social or organisational features of a job that help achieve work goals, decrease the effect of job demands and enhance personal development and learning (Bakker, Demerouti and Schaufeli 2003; Bakker, Van Veldhoven and Xanthopoulou 2010).

In a similar vein, it can be useful to also classify aspects associated with studying at university as study demands and study resources. This is based on the assumption that students' studies can be considered as their work because, as employees, students are also involved in structured, organised and coercive activities such as studying for tests, completing assignments and attending classes. These activities also are directed toward a specific goal, which may include getting good grades, passing exams, or obtaining a degree (Ouweneel, LeBlanc and Schaufeli 2011).

Student engagement can be described as an on-going and positive affectivemotivational state accomplished by an individual, which includes two core components, namely vigour and dedication (Schaufeli 2005; Schaufeli and Salanova 2007; Schaufeli et al. 2002; Zhang, Gan and Cham 2007). Vigour is characterised by high levels of energy and mental resilience while working, and an individuals' ability and enthusiasm to invest effort in their work or studies. Dedication refers to being fully involved in work or studies, and experience a sense of meaning, motivation, enthusiasm, pride and challenge (Bakker 
and Bal 2010).

In the organisational context, studies showed that job demands and job resources are related differently to work engagement. Job resources have a very strong and positive relationship with work engagement, while job demands have a weaker and negative relationship with engagement (Bakker, Demerouti and Euwema 2005; Crawford, LePine and Rich 2010). Job demands can deplete energy levels and is therefore associated with higher levels of burnout, the opposite of work engagement (Bakker and Demerouti 2007; Crawford, LePine and Rich 2010). On the other hand, job resources, including resources such as information, appreciation, organisational climate, innovativeness and supervisor support, facilitate work engagement (Bakker et al. 2007).

The findings of these work-related studies were largely confirmed in the academic context (Mokgele and Rothmann 2014; Salmela-Aro and Upadyaya 2014; Wolff et al. 2014). For example, in a study amongst first-year psychology students from a tertiary institution in the Netherlands, Bakker, Vergel and Kuntze (2015) showed that the motivational process also exist and can be applied in the academic context. More specifically, they found that both the personal and environmental resources of students can influence student engagement. It therefore seems that student demands are negatively related to student engagement (Hypothesis 1) and student resources are positively related to student engagement (Hypothesis 2).

\section{Engagement and personality characteristics}

Personality can be defined as the unique psychological qualities that contribute to the way an individual feels, thinks and behaves (Louw 2014; Pervin and Cervone 2010). Personality influences how individuals interpret their environment and actively search for selfregulatory strategies or approaches to help them adapt successfully to the various demands (Zecca et al. 2015). Personality can also be viewed as a system defined by various personality traits and dynamic processes, which influence how people function socially and in their work environment (Gatewood, Field and Barrick 2011; Louw 2014).

There is a strong link between personality and work engagement ( $\mathrm{Li}$ and Mao 2014; Kim, Shin and Swanger 2009; Rossier et al. 2012). Although all personality characteristics are important, it seems that specific personality characteristics have a stronger relationship with work engagement and performance, including neuroticism, extraversion, conscientiousness and intellect-openness (Akhtar et al. 2015; Aluja, Kuhlman and Zuckerman 2010; Nilforooshan and Salimi 2016; Ongore 2014; Rogers, Creed and 
Glendon 2008; Woods and Sofat 2013). In a study amongst 1050 working adults, Akhtar et al. (2015) found that personality traits are valid predictors of work engagement. Similarly, Inceoglu and Warr (2012) found in a sample of 393 individuals from several countries that particularly conscientiousness and extraversion are strong predictors of work engagement. With regards to student's engagement and academic performance, it was also established that personality play a significant role (Ariani 2015; Paunonen and Ashton 2001; Poropat 2009; Rosander and Bäckström 2014; Salanova et al. 2009; Uppal and Mishra 2014).

For the purposes of this study, the following personality dimensions and sub-facets were regarded as most relevant for student engagement (definitions are based on Hill et al. 2013):

- Extraversion (sociability): the tendency to be outgoing and spontaneous, where individuals enjoy having people around them and to communicate with others.

- Conscientiousness (achievement orientation): an orientation towards achieving things in life, by working hard and being directed towards whatever an individual wants to obtain.

- Conscientiousness (orderliness): characteristic of individuals being precise and thorough in what they do, acting tidily, punctually and well-organised.

- Neuroticism (emotional balance): striking the correct balance between pleasant and unpleasant feelings.

- Neuroticism (negative emotionality): the antithesis of positive thinking. Negative emotionality implies a propensity for depression and anxiety, and a tendency to react with unpleasant emotions to stressful situations.

Based on previous studies, all these personality dimensions are positively related to academic performance, except for neuroticism, which has a negative relationship with engagement (Bauer and Liang 2003; Di Fabio and Busoni 2007; Downey et al. 2014). It is therefore reasonable to expect that these specific personality dimensions will also predict student engagement, in addition to study demands and study resources. It is therefore hypothesised that sociability (a facet of extraversion), achievement orientation and orderliness (facets of conscientiousness) and emotional balance and negative emotionality (facets of neuroticism) are significant predictors of student engagement (Hypothesis 3). 


\section{RESEARCH DESIGN}

\section{Research design, participants and procedure}

A cross-sectional research design was used. A sample of first-year university students were used $(N=512)$. Permission was obtained from the Registrar and Student Deans on different campuses, after ethical clearance was obtained. An email was sent to a randomly selected group of first-year students. This email contained a web-based link that directed students to an electronic website. On the website, the goal and purpose of the study was explained, as well as the research procedure, ethical issues, the importance of the study and the value of their participation to the research and university. Participants were assured of confidentiality, voluntary participation, and the possibility to complete the questionnaire in their own free time. They were also asked to complete an electronic informed-consent form.

The sample was stratified in terms of three campuses of the university. The sample consisted of more female participants (58.40\%) than male participants (39.50\%). The majority of the sample included Black (59.00\%) and White (37.50\%) students who spoke Afrikaans (36.70\%) and Setwana (28.50\%). Most students either stayed in off-campus residences (39.30\%); 27.90 per cent reside on campus and live in a hostel; 24.20 per cent reside off-campus and is part of a town residence. Most participants (50.60\%) indicated that they are first-entry students.

\section{Measuring instruments}

The research made use of various measuring instruments, as expounded below.

\section{Student demands and resources}

Study demands and resources were measured by an adapted version of the questionnaire on the experience and assessment of work (VBBA) (Van Veldhoven et al. 1997) to fit the academic context. A four-point Likert scale was used, ranging from 0 (almost never) to 3 (almost always). Study demands included: pace and amount of work in studies (five items, e.g. 'How often do you have to work extra hard in order to complete something?'); and cognitive demands (six items, e.g. 'How often do you feel that the tasks that you have to complete for your studies are too difficult?'). Study resources included: support from family (three items, e.g. 'If necessary, can you ask your family for help?'); support from lecturers (three items, e.g. 'When I encounter problems with my course, I can ask my 
lecturers for advice'); support from friends (four items, e.g. 'Do your friends support you?'); and opportunities for growth and development (four items, e.g. 'Do your studies give you the feeling that you can achieve something with your life?'). Studies using the VBBA measuring demands and resources of employees found the scales valid and reliable (Van Veldhoven et al. 2002; Van Veldhoven et al. 2005).

\section{Student engagement}

The Utrecht Work Engagement Scale-Student Survey (UWES-S) (Schaufeli et al. 2002) was used to measure student engagement. A seven-point Likert-type scale was used, ranging from 0 (never) to 6 (every day). Five items were used to measure vigour (e.g. 'Even when studying becomes difficult, I have the mental energy to keep going on'), while six items were used to measure dedication levels (e.g. 'I am excited about my studies'). The UWES has been found to valid and reliable in the South African context with Cronbach's alpha coefficients ranging between 0.70 to 0.78 for vigour and 0.78 to 0.89 for dedication (Mostert et al. 2007; Storm and Rothmann 2003).

\section{Personality characteristics}

The South African Personality Inventory (SAPI) (Fetvadjiev et al. 2015) was used to measure the following personality characteristics: sociability (a facet of extraversion; seven items, e.g. 'I connect with people easily'); two facets of conscientiousness, achievement orientation (11 items, e.g. 'I am determined in the things I do') and orderliness (13 items, 'I check for errors in work that has been done'); and two facets of neuroticism, emotional balance (eight items, e.g. 'I can deal with difficulties in my life'); and negative emotionality (ten items, e.g. 'I am afraid that bad things may happen'). Fetvadjiev et al. (2015) found acceptable Cronbach's alpha coefficients for extraversion (sociability): $\alpha=0.81$; conscientiousness (achievement orientation): $\alpha=0.80$; conscientiousness (orderliness): $\alpha$ $=0.85$; neuroticism (emotional balance): $\alpha=0.74$; and neuroticism (negative emotionality): $\alpha=0.75$. The responses were measured on a five-point Likert scale, ranging from 1 (Strongly Disagree) to 5 (Strongly Agree).

\section{Statistical analysis}

The statistical analysis of the present study was carried out by means of the SPSS programme (IBM SPSS 2013) and Mplus 7.2 (Muthén and Muthén 2014). First, confirmatory factor analysis (CFA) was used to determine factorial validity with Mplus. 
The fit indices used to assess mode fit were: Comparative Fit Index (CFI), Root Mean Square Error of Approximation (RMSEA), Tucker-Lewis Index (TLI), Akaike Information Criterion (AIC), Bayesian Information Criterion (BIC), and Standardised Root Mean Square Residual (SRMR). For an acceptable model fit, the values of both the CFI and TLI must be above the threshold of 0.90 (Byrne 2001; Hoyle 1995). With regards to the RMSEA, a value under the cut-off threshold of 0.08 indicates good model fit (Browne and Cudeck 1993). The AIC and BIC were used to compare different models - the model with the lowest AIC and BIC value indicates best model fit. The cut-off point for the SRMR is less than 0.05 (Hu and Bentler 1999).

Means, standard deviations, Cronbach's alpha coefficients and Pearson's productmoment correlations coefficients were calculated using SPSS. A hierarchical multiple regression analysis was used to relate the dependent variable (student engagement) to the independent variables (study demands, study resources and personality characteristics).

\section{RESULTS}

Before testing the regression model, different measurement models were tested with CFA to ensure factorial validity for study demands, study resources and student engagement. First, a two-factor model for study demands and resources were tested, specifying the items of pace and amount of work and cognitive demands loading on the first factor, labelled 'study demands', while the items of family support, lecturer support, friend support and opportunities for growth and development loaded on the second factor, labelled 'study resources'. With regards to student engagement, two competing measurement models were tested: A two-factor model, with the items of vigour loading on one factor and the items of dedication loading on the second; and a one-factor model, with all the engagement items loading on one 'student engagement' factor. The final measurement model was tested that included study demands, study resources and student engagement. The results of these analysis are presented in Table 1.

Table 1: Results of measurement models for engagement

\begin{tabular}{|l|c|c|c|c|c|c|c|}
\hline Model & $\boldsymbol{d f}$ & CFI & TLI & RMSEA & SRMR & AIC & BIC \\
\hline Study demands and resources & 870 & 0.91 & 0.89 & 0.04 & 0.05 & 64424.69 & 65314.73 \\
\hline Engagement one-factor model & 43 & 0.92 & 0.90 & 0.12 & 0.04 & 17055.73 & 17199.83 \\
\hline Engagement two-factor model & 42 & 0.93 & 0.90 & 0.11 & 0.04 & 17026.21 & 17174.55 \\
\hline Total measurement model & 573 & 0.90 & 0.89 & 0.05 & 0.05 & 44294.55 & 44841.3 \\
\hline
\end{tabular}

Notes: $d f$ = degrees of freedom; CFI = Comparative fit index; TLI = Tucker-Lewis index; RMSEA = Root mean square error of approximation; $\mathrm{AIC}=$ Akaike Information Criterion; BIC = Bayesian Information Criterion

The results presented in Table 1 show reasonable good fit for the measurement model of 
study demands and resources. Although both measurement models for student engagement showed acceptable fit (CFI and TLI values were above 0.90, but RMSEA values were above 0.08 ), the correlation of $r=0.95$ between vigour and dedication was very high (Brown 2015). As a result, it was decided to continue using a one-factor engagement construct. The descriptive statistics, product moment correlation coefficients and Cronbach's alpha coefficients are presented in the Table 2.

As can be seen in Table 2, all the scales showed good internal consistency with Cronbach's alpha coefficients $>0.70$. All the study demands and resources showed a statistically significant relationship with student engagement (study demands negative and study resources positive). The relationship between growth and development and student engagement had a positive and practically significant relationship with student engagement, with medium effect. Sociability_and negative emotionality had a statistically significant relationship with engagement, positive and negative respectively. Orderliness and emotional balance had a practically significant (medium effect) and positive relationship with engagement, while achievement orientation indicated a practically significant (large effect) and positive relationship with student engagement. The results of the multiple regression analysis is reported in Table 3.

In the first step of the regression analysis, gender, ethnicity and whether respondents are first-generation students were entered as control variables. The entry of the control variables in the first step of the regression analysis produced a statistically significant model $(F 4.940=4.94 ; p=0.00)$, which accounted for approximately 4 per cent of the variance in engagement. Gender $(\beta=-0.11 ; t=-2.51 ; p \leq 0.05)$ and the status of firstgeneration student $(\beta=0.14 ; t=3.03 ; p \leq 0.05)$ were significant predictors of engagement in this step.

Pace and amount of work and cognitive demands were added in the second step. This also produced a statistically significant model $(F 17.016=9.18 ; p=0.00)$, accounting for an additional 6 per cent of the variance in engagement. Significant predictors of student engagement in this step were the status of being a first-generation student $(\beta=0.12 ; t=$ 2.74; $p \leq 0.05)$ and cognitive demands $(\beta=-0.20 ; t=-3.90 ; p \leq 0.05)$.

Study resources were included in the third step of the model. This was also a statistically significant model $(F 28.735=18.25 ; p=0.00)$, accounting for an additional 17 
Table 2: Descriptive statistics, product moment correlation coefficients and Cronbach's alpha coefficients (Cronbach's alpha coefficients showed on the diagonal)

\begin{tabular}{|c|c|c|c|c|c|c|c|c|c|c|c|c|c|}
\hline & $M$ & SD & 1 & 2 & 3 & 4 & 5 & 6 & 7 & 8 & 9 & 10 & 11 \\
\hline 1 Pace and amount & 2.67 & 0.54 & 0.72 & & & & & & & & & & \\
\hline 2 Cognitive demands & 2.35 & 0.54 & $0.52^{\star \star}$ & 0.77 & & & & & & & & & \\
\hline 3 Family support & 3.24 & 0.81 & $-0.17^{\star *}$ & $-0.13^{\star \star}$ & 0.79 & & & & & & & & \\
\hline 4. Lecturer support & 2.67 & 0.90 & $-0.15^{\star \star}$ & $-0.30 * *$ & $0.21^{\star *}$ & 0.86 & & & & & & & \\
\hline 5 Friend support & 3.00 & 0.76 & $-0.20 \star \star$ & $-0.16^{\star \star}$ & $0.23^{\star *}$ & $0.22^{\star \star}$ & 0.85 & & & & & & \\
\hline 6 Growth and development & 3.61 & 0.49 & $-0.12^{\star \star}$ & $-0.20 * *$ & $0.12^{\star \star}$ & $0.30^{\star *}$ & $0.103^{*}$ & 0.76 & & & & & \\
\hline \multirow{2}{*}{$\begin{array}{l}7 \text { Extraversion: } \\
\text { Sociability }\end{array}$} & 3.56 & 0.87 & \multirow{2}{*}{0.00} & \multirow{2}{*}{-0.05} & \multirow{2}{*}{-0.06} & \multirow{2}{*}{0.18} & \multirow{2}{*}{0.22} & \multirow{2}{*}{0.13} & \multirow{2}{*}{0.89} & & & & \\
\hline & 4.23 & 0.58 & & & & & & & & & & & \\
\hline \multirow{2}{*}{$\begin{array}{c}8 \text { Achievement } \\
\text { Orientation }\end{array}$} & 4.11 & 0.56 & \multirow{2}{*}{$-0.11^{*}$} & \multirow{2}{*}{$-0.22^{\star \star}$} & \multirow{2}{*}{$0.12^{\star \star}$} & \multirow{2}{*}{$0.26^{\star \star}$} & \multirow{2}{*}{$0.12^{\star \star}$} & \multirow{2}{*}{$0.33^{\star *}$} & \multirow{2}{*}{$0.32^{\star \star}$} & \multirow{2}{*}{0.91} & & & \\
\hline & 4.07 & 0.64 & & & & & & & & & & & \\
\hline 9 Orderliness & 2.89 & 0.78 & $-0.12^{\star \star}$ & $-0.19 * \star$ & $0.14^{\star *}$ & $0.28 * \star$ & $0.13^{\star *}$ & $0.30^{\star *}$ & $0.16^{\star \star}$ & $0.71^{\star *}$ & 0.90 & & \\
\hline 10 Emotional balance & 4.59 & 1.14 & $-0.12^{\star \star}$ & $-0.16^{\star \star}$ & $0.12^{\star *}$ & $0.13^{\star *}$ & $0.15^{\star \star}$ & $0.24^{\star *}$ & $0.32^{\star \star}$ & $0.49 \star \star$ & $0.49 * *$ & 0.87 & \\
\hline 11 Negative emotionality & & & $0.19^{\star \star}$ & $0.30 * \star$ & $-0.11^{*}$ & $-0.21^{\star \star}$ & $-0.17^{\star *}$ & $-0.13^{* *}$ & $-0.16^{\star \star}$ & $-0.13^{\star \star}$ & $-0.18^{\star *}$ & $-0.35^{\star \star}$ & 0.85 \\
\hline 12 Engagement & & & 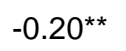 & $-0.26^{\star \star}$ & $0.12^{\star *}$ & $0.28 * \star$ & $0.15^{\star \star}$ & $0.45^{\star \star}$ & $0.17^{\star \star}$ & $0.51^{\star *}$ & $0.43^{\star \star}$ & $0.35^{\star \star}$ & $-0.22^{\star *}$ \\
\hline
\end{tabular}

* Statistically significant, $p \leq 0.05$

* Statistically significant, $p<0.01$

Practically significant - medium effect $>0.30$

Practically significant - large effect $\geq 0.50$ 
Table 3: Multiple regression analysis with engagement as the dependent variable

\begin{tabular}{|c|c|c|c|c|c|c|c|c|c|c|}
\hline \multirow{2}{*}{\multicolumn{2}{|c|}{ Model }} & \multicolumn{2}{|c|}{$\begin{array}{c}\text { Unstandardised } \\
\text { coefficients }\end{array}$} & \multirow{2}{*}{$\begin{array}{c}\begin{array}{c}\text { Standardised } \\
\text { coefficients }\end{array} \\
\text { BETA }\end{array}$} & \multirow[t]{2}{*}{$t$} & \multirow[t]{2}{*}{$p$} & \multirow[t]{2}{*}{$\boldsymbol{F}$} & \multirow[t]{2}{*}{$R$} & \multirow[t]{2}{*}{$R^{2}$} & \multirow[t]{2}{*}{$\Delta R^{2}$} \\
\hline & & $B$ & SE & & & & & & & \\
\hline \multirow[t]{5}{*}{1} & (Constant) & 4.68 & 0.18 & & 25.94 & $0.00^{*}$ & 4.94 & 0.20 & 0.04 & 0.04 \\
\hline & Gender & -0.26 & 0.10 & -0.11 & -2.51 & $0.01^{*}$ & & & & \\
\hline & Ethnicity & 0.01 & 0.04 & 0.01 & 0.13 & 0.90 & & & & \\
\hline & Campus & -0.05 & 0.08 & -0.03 & -0.67 & 0.50 & & & & \\
\hline & First-generation student & 0.32 & 0.11 & 0.14 & 3.03 & $0.00^{*}$ & & & & \\
\hline \multirow[t]{7}{*}{2} & (Constant) & 6.19 & 0.32 & & 19.19 & $0.00^{*}$ & 9.18 & 0.32 & 0.10 & 0.06 \\
\hline & Gender & -0.17 & 0.10 & -0.8 & -1.71 & 0.09 & & & & \\
\hline & Ethnicity & -0.04 & 0.04 & -0.05 & -1.17 & 0.24 & & & & \\
\hline & Campus & -0.03 & 0.07 & -0.02 & -0.36 & 0.72 & & & & \\
\hline & First-generation student & 0.28 & 0.10 & 0.12 & 2.74 & $0.01^{*}$ & & & & \\
\hline & $\begin{array}{l}\text { Pace and amount of } \\
\text { work }\end{array}$ & -0.19 & 0.11 & -0.09 & -1.79 & 0.08 & & & & \\
\hline & Cognitive demands & -0.42 & 0.11 & -0.20 & -3.90 & $0.00^{*}$ & & & & \\
\hline \multirow[t]{11}{*}{3} & (Constant) & 1.69 & 0.53 & & 3.16 & $0.00^{*}$ & 18.25 & 0.52 & 0.27 & 0.17 \\
\hline & Gender & -0.18 & 0.09 & -0.08 & -1.95 & $0.05^{*}$ & & & & \\
\hline & Ethnicity & -0.07 & 0.03 & -0.09 & -2.01 & $0.05^{\star}$ & & & & \\
\hline & Campus & -0.06 & 0.07 & -0.03 & -0.81 & 0.42 & & & & \\
\hline & First-generation student & 0.24 & 0.09 & 0.11 & 2.62 & $0.01^{*}$ & & & & \\
\hline & $\begin{array}{l}\text { Pace and amount of } \\
\text { work }\end{array}$ & -0.14 & 0.10 & -0.07 & -1.41 & 0.16 & & & & \\
\hline & Cognitive demands & -0.20 & 0.10 & -0.10 & -2.02 & $0.04^{*}$ & & & & \\
\hline & Support from family & 0.08 & 0.06 & 0.06 & 1.39 & 0.17 & & & & \\
\hline & Support from lecturer & 0.14 & 0.06 & 0.11 & 2.63 & $0.01^{*}$ & & & & \\
\hline & Support from friends & 0.10 & 0.06 & 0.07 & 1.61 & 0.11 & & & & \\
\hline & $\begin{array}{l}\text { Opportunities to } \\
\text { grow and develop }\end{array}$ & 0.84 & 0.10 & 0.36 & 8.68 & $0.00^{*}$ & & & & \\
\hline \multirow[t]{16}{*}{4} & (Constant) & -0.69 & 0.61 & & -1.12 & 0.26 & 19.82 & 0.62 & 0.38 & 0.11 \\
\hline & Gender & -0.14 & 0.9 & -0.06 & -1.59 & 0.11 & & & & \\
\hline & Ethnicity & -0.01 & 0.03 & -0.02 & -0.43 & 0.67 & & & & \\
\hline & Campus & -0.05 & 0.06 & -0.03 & -0.81 & 0.42 & & & & \\
\hline & $\begin{array}{l}\text { First-generation } \\
\text { student }\end{array}$ & 0.23 & 0.09 & 0.10 & 2.69 & $0.01^{*}$ & & & & \\
\hline & $\begin{array}{l}\text { Pace and amount of } \\
\text { work }\end{array}$ & -0.15 & 0.09 & -0.07 & -1.62 & 0.11 & & & & \\
\hline & Cognitive demands & -0.09 & 0.10 & -0.04 & -0.90 & 0.37 & & & & \\
\hline & Support from family & 0.03 & 0.05 & 0.02 & 0.57 & 0.57 & & & & \\
\hline & Support from lecturer & 0.08 & 0.05 & 0.06 & 1.52 & 0.13 & & & & \\
\hline & Support from friends & 0.06 & 0.06 & 0.04 & 1.0 & 0.32 & & & & \\
\hline & $\begin{array}{l}\text { Opportunities to grow } \\
\text { and develop }\end{array}$ & 0.63 & 0.09 & 0.27 & 6.72 & $0.00^{*}$ & & & & \\
\hline & $\begin{array}{l}\text { Extraversion: } \\
\text { Sociability }\end{array}$ & -0.02 & 0.05 & -0.02 & -0.38 & 0.70 & & & & \\
\hline & $\begin{array}{l}\text { Conscientiousness: } \\
\text { Achievement } \\
\text { orientation }\end{array}$ & 0.57 & 0.11 & 0.27 & 5.14 & $0.00^{*}$ & & & & \\
\hline & \begin{tabular}{|l} 
Conscientiousness: \\
Orderliness
\end{tabular} & 0.13 & 0.11 & 0.06 & 1.11 & 0.27 & & & & \\
\hline & $\begin{array}{l}\text { Neuroticism: Emotional } \\
\text { balance }\end{array}$ & 0.11 & 0.08 & 0.06 & 1.33 & 0.18 & & & & \\
\hline & $\begin{array}{l}\text { Neuroticism: Negative } \\
\text { emotionality }\end{array}$ & -0.03 & 0.06 & -0.02 & -0.51 & 0.61 & & & & \\
\hline
\end{tabular}


per cent of the variance in student engagement. In this model, significant predictors of student engagement were: gender $(\beta=-0.08 ; t=-1.95 ; p \leq 0.05)$; ethnicity $(\beta=-0.09 ; t=$ $-2.01 ; p \leq 0.05)$; the status of first-generation student $(\beta=0.11 ; t=2.62 ; p \leq 0.05)$; cognitive demands $(\beta=-0.10 ; t=-2.02 ; p \leq 0.05)$; support from lecturers $(\beta=0.11 ; t=2.63 ; p \leq$ $0.05)$; and opportunities for growth and development ( $\beta=0.36 ; t=8.68 ; p \leq 0.05)$.

Personality characteristics were added in the final step of the regression analysis. This step explained an additional 11 per cent of the variance in student engagement. The following variables were significant predictors of student engagement: the status of firstgeneration student $(\beta=0.10 ; t=2.69 ; p \leq 0.05)$; opportunities to learn and grow $(\beta=0.27$; $t=6.72 ; p \leq 0.05$ ); and conscientiousness (achievement orientation) $(\beta=0.27 ; t=5.14 ; p$ $\leq 0.05)$. In total, the final step explained 38 per cent of the variance in student engagement.

\section{DISCUSSION}

The main objective of this study was to investigate significant predictors of student engagement, including study demands, study resources and personality characteristics (as measured by the South African Personality Inventory) in a sample of 512 South African first-year university students.

The results of the product-moment correlations showed that study demands and student engagement were significantly related. Both demands - pace and amount of work and cognitive demands - had a statistical significant (negative) relationship with student engagement. After controlling for certain socio-demographic characteristics, these two study demands accounted for 6 per cent of the variance in student engagement, although cognitive demands seemed to be the only study demand that significantly predicted student engagement in the regression analysis (although it became insignificant in the fourth step when personality characteristics were added). It therefore appears that cognitive demands is an important demand to consider when studying student engagement. When students have to remember many things simultaneously, have to concentrate for very long periods at a time, and feel that their academics are very challenging and too difficult to handle, they will most probably also experience lower levels of energy and dedication to their studies. This is in line with previous studies that showed how high cognitive demands can deplete energy levels (Boswell, Olson-Buchanan and LePine 2004; Cavanaugh et al. 2000). Based on these results, partial support was found for Hypothesis 1, which stated that study demands have a significant and negative relationship with student engagement.

With regards to the relationship between study resources and student engagement, the 
product-moment correlations showed that all study resources were significantly and positively related to student engagement, specifically opportunities for growth and development. Study resources accounted for an additional 17 per cent of the variance, emphasising the importance of resources in predicting student engagement. However, only opportunities for growth and development $(\beta=0.36)$ and support from lecturers $(\beta=0.11)$ were significant predictors of student engagement in the third step of the regression analysis, while opportunities for growth and development was the only significant study resource predicting student engagement in the final step when personality characteristics were included $(\beta=0.27)$.

These findings are in line with previous studies. Several studies showed that resources are positively related to engagement and are the most important predictors of learning, commitment, work motivation and engagement (Bakker et al. 2007; Bakker et al. 2010; Bakker, Demerouti and Euwema 2005; Crawford et al. 2010). With regards to the relationship between support from lecturers and student engagement, previous studies showed that performance feedback, and a supportive supervisor, or in the academic context a supportive lecturer, makes it more likely that individuals will attain their goals and be successful (Bakker, Albrecht and Leiter 2011). This is mainly because proper and appropriate feedback foster growth and learning, which ultimately increases individuals' believe in themselves to accomplish work-related goals (Bakker and Demerouti 2008). Particularly, in the academic context, feedback from a lecturer can help students improve their performance and assist them to complete their studies successfully (Ouweneel et al. 2011). Furthermore, in a sample of 12359 employees in various organisations, a previous study showed how performance feedback, learning possibilities and career opportunities promote the need for competence, which in return help achieving work-related goals (Bakker, Van Veldhoven and Xanthopoulou 2010).

Of the study resources included in this study, opportunities for growth and development had the strongest relationship with student engagement. It was also the only resource that was a significant predictor in the final step of the regression analysis. This relates to previous studies that showed how people, when they have sufficient opportunities for professional growth and development, are more intrinsically motivated to reach their goals and improve performance (Bakker 2009; Bakker and Demerouti 2007; Schaufeli and Bakker 2004). It is also associated with putting more effort into a task (Gagné and Deci 2005) and is essential for competence, curiosity and thoroughness (McCauley, Ruderman, Ohlott and Morrow 1994). Within the academic context, opportunities to grow and develop 
may also create positive psychological states such as meaningfulness, knowledge and responsibility (Mokgele and Rothmann 2014).

In this study, support from family and friends were not significant predictors of student engagement. This finding is in contrast with previous findings that clearly showed how support from students' family and friends have a significant impact on their academic performance and academic engagement (Christenson and Thurlow 2004; Yang 2004). A study by Yang (2004) on the academic achievement of school learners showed that daily performance and behaviour at school are strongly influenced by student's support structures, specifically when parents are involved in their children's lives. These findings showed partial support for Hypothesis 2, which stated that student resources have a significant positive relationship with student engagement.

In this study, personality characteristics and student engagement had a strong relationship, specifically three dimensions (according to the product-moment correlations): achievement orientation ( $r=0.51)$, orderliness $(r=0.43)$ and emotional balance $(r=0.35)$. However, in the final step of the multiple regression analysis, only one facet of conscientiousness, achievement orientation, was a significant predictor of student engagement. This is in line with previous studies that showed achievement orientation plays a valuable role in students' study habits and engagement (Chamorro-Premuzic and Furnham 2003; McCrae and Costa 2003; Rosander and Bäckström 2014). Achievement orientation was also the strongest predictor of engagement in other research studies (Inceoglu and Warr 2012). When individuals are achievement oriented, they have the aspiration to accomplish challenging tasks and the willingness to put effort in their work (McClelland 1985). An individual who is achievement oriented also knows and understands the importance of continuous learning, development and improvement, all aspects associated with engagement (Maurice Kerrigan Africa 2013).

Previous research showed that personality can motivate learning and as well as influence students' academic performance (Abolmaali, Rashedi and Ajilchi 2014). Although significant correlations were reported between extraversion and neuroticism with student engagement, these personality characteristics were not significant predictors of student engagement in this study. This is, however, contrary to the previous studies. Several studies found that extraversion has a positive relationship with engagement, mainly since both these elements contain dimensions of energy and dynamic behaviour (Langelaan et al. 2006; Sulea et al. 2015; Zecca et al. 2015). Extraverted individuals are more likely to experience positive emotions, which may help them build personal resources that can 
contribute to engagement (Fredrickson 1998; Sulea et al. 2015). People who rate high on the sociability dimension of extraversion, communicate confidently with others and are able to build important connections and networks in their work, which in turn can help them advance their careers (Bezuidenhout 2011; Potgieter and Coetzee 2013). These people are also more likely to seek feedback that help them improve their performance and reach their goals (Bezuidenhout 2011; Potgieter and Coetzee 2013).

With regards to neuroticism, previous studies showed that it is negatively related to work engagement (Nilforooshan and Salimi 2016). Explanations offered for this negative relationship include that neuroticism is related strongly to anxiety, depression, negative thoughts, pessimism and low self-esteem, which all can negatively influence work engagement (Aluja, Kuhlman and Zuckerman 2010; Nilforooshan and Salimi 2016). Individuals who score high on neuroticism may also be less willing to embrace new experiences or see the need for growth and development (Nilforooshan and Salimi 2016). Based on these findings, only partial support was found for Hypothesis 3, which stated that extraversion (sociability), conscientiousness (achievement orientation and orderliness) and neuroticism (emotional balance and negative emotionality) are significant predictors of student engagement.

\section{CONCLUSIONS}

The results of this study highlights the importance of support from lecturers and especially opportunities for growth and development for student engagement. Also, specifically achievement orientation (a facet of conscientiousness) is important to consider in predicting student engagement. This emphasises the important role conscientiousness (diligence and willingness to work hard) plays in student engagement. In total, the variables included in the regression analysis explained 38 per cent of the variance in student engagement, indicating that it is indeed worthwhile to study the role of study demands, study resources and personality characteristics on students’ engagement.

\section{Limitations and recommendations}

The current research followed a cross-sectional design. In other words, data were gathered only at a specific point in time, which implies that behaviour could not be measured over an extended period. The present study was therefore restricted in determining cause and effect over a longer period. A longitudinal design can be recommended for future research in which data is gathered repeatedly on the same individuals over an extended period 
(Govindji and Linley 2007). The characteristics of the sample (i.e., first-year students at a specific university) is very specific, limiting generalisability of the results to other year groups and educational settings. Future studies could include first-year students from other tertiary institutions and also senior students. The study also utilised self-reported measures, therefore participants' understanding and interpretation of the questions and rating scales may differ.

It is recommended that future researchers include additional demands and resources in their studies. Pertaining to cognitive demands, it is suggested that further research investigate the elements that influence cognitive demands. The degree of cognitive demands may differ between students. More research is needed to understand the relationship between cognitive demands and student engagement. It is also important to keep in mind that the transition from secondary to tertiary education is a significant adjustment and challenging experience for first-year students (Asghar 2014; Eagan, Lozano, Hurtado and Case 2013). It is therefore important for universities and students to work together to manage the cognitive (and other) demands that first-year students experience. Although the role of the University is imperative, students should also realise that they should be proactive in dealing with this challenge and use available resources to assist them with their demands and realise their own responsibility in facilitating their engagement and success in their studies.

The results of the present study also raised valid questions about the role of personality characteristics in student engagement. Following the results of the regression analysis, it must be pointed out that, although the final step explained an additional 11 per cent of the variance in student engagement, the model in this step was not statistically significant. This may be due to several reasons, including possible multicollinearity (high correlations) between the personality dimensions and the fact that the individual $t$-test statistics and the overall F-statistic answer different questions. It is recommended that future studies examine these issues to shed more light on the influence of the personality characteristics on student engagement and the role that the student him or herself should play in engaging in his or her studies. The optimal result would therefore be for the University to be aware of the effect of demands on student engagement and provide the necessary institutional resources for students in order for them to deal with demands. However, it is also clear that personality plays a significant role in predicting student engagement. Therefore, students should also take responsibility themselves and proactively utilise the resources that are provided to them and seek out opportunities that will facilitate their engagement in their 
studies.

The results of the present study make an important contribution to the literature and the field of student engagement. Additional information has been made available on the impact that study demands, study resources and personality characteristics have on student engagement. These findings can benefit both the students and the university. The benefits for students may include higher engagement with their studies, finding a meaningful connection with their studies, learning to cope better with certain demands they may face, and improving academic performance. On the other side of the coin, universities have a clearer understanding of the role that demands, resources and personality play and how supporting structures can improve the engagement levels of their students. The findings can also help universities develop possible supporting programmes or structures that could assist students in coping with various demands and daily challenges. More specifically, to reduce the effect of cognitive demands on students, the universities can implement interventions that could help students handle such demands successfully. This may ultimately improve students' performance and engagement. Universities can collaborate with lecturers to identify gaps and then provide students with more opportunities for growth and development in their work and studies. Finally, it is important that universities consider the significance of conscientiousness since this personality characteristic is clearly an important predictor of student engagement, particularly for first-year entries.

\section{AUTHOR'S NOTE}

Jeanie Cilliers wrote the manuscript as part of her master's dissertation at the North-West University, Potchefstroom Campus, South Africa. The material described in this article is based upon work supported by the National Research Foundation under reference number ERSA13112658399 (Grant No: 90396). The views and opinions expressed in this research are those of the researcher and do not reflect the opinion or views of the National Research Foundation.

\section{REFERENCES}

Abolmaali, K., M. Rashedi and B. Ajilchi. 2014. Explanation of academic achievement based on personality characteristics psycho-social climate of the classroom and students' academic engagement in mathematics. Open Journal of Applied Sciences 4(5): 225-233.

Akhtar, R., L. Boustani, D. Tsivrikos and T. Chamorro-Premuzic. 2015. The engageable personality: Personality and trait EI as predictors of work engagement. Personality and Individual Differences 73: 44-49.

Aluja, A., M. Kuhlman and M. Zuckerman. 2010. Development of the Zuckerman-Kuhlman-Aluja Personality Questionnaire (ZKA-PQ): A factor/facet version of the Zuckerman-Kuhlman 
Personality Questionnaire (ZKPQ). Journal of Personality Assessment 92(5): 416-431.

Ariani, D. W. 2015. Relationship model of personality, communication, student engagement and learning satisfaction. Business, Management and Education 13(2): 175-202.

Asghar, H. 2014. Patterns of engagement and anxiety in university students: First year to senior year. Psychology Applications \& Developments Advances in Psychology and Psychological Trends Series, ed. Clara Pracana, 248.

Bakker, A. B. 2009. Building engagement in the workplace. In The peak performing organization, ed. C. L. Cooper and R. J. Burke, 50-72. Oxon, UK: Routledge.

Bakker, A. B., S. L. Albrecht and M. P. Leiter. 2011. Key questions regarding work engagement. European Journal of Work and Organizational Psychology 20(1): 4-28.

Bakker, A. B. and M. P. Bal. 2010. Weekly work engagement and performance: A study among starting teachers. Journal of Occupational and Organizational Psychology 83(1): 189-206.

Bakker, A. B. and E. Demerouti. 2007. The job demands-resources model: State of the art. Journal of Managerial Psychology 22(3): 309-328.

Bakker, A. B. and E. Demerouti. 2008. Towards a model of work engagement. Career Development International 13(3): 209-223.

Bakker, A. B., E. Demerouti and M. C. Euwema. 2005. Job resources buffer the impact of job demands on burnout. Journal of Occupational Health Psychology 10(2): 170.

Bakker, A., E. Demerouti and W. Schaufeli. 2003. Dual processes at work in a call centre: An application of the job demands-resources model. European Journal of Work and Organizational Psychology 12(4): 393-417.

Bakker, A. B., J. J. Hakanen, E. Demerouti and D. Xanthopoulou. 2007. Job resources boost work engagement, particularly when job demands are high. Journal of Educational Psychology 99(2): 274.

Bakker, A. B., M. van Veldhoven and D. Xanthopoulou. 2010. Beyond the demand-control model thriving on high job demands and resources. Journal of Personnel Psychology 9(1): 3-16.

Bakker, A. B., A. I. S. Vergel and J. Kuntze. 2015. Student engagement and performance: A weekly diary study on the role of openness. Motivation and Emotion 39(1): 49-62.

Bauer, K. W. and Q. Liang. 2003. The effect of personality and precollege characteristics on first-year activities and academic performance. Journal of College Student Development 44(3): 277-290.

Bezuidenhout, M. 2011. The development and evaluation of a measure of graduate employability in the context of the new world of work. Unpublished master's dissertation, University of Pretoria.

Boswell, W., J. Olson-Buchanan and M. LePine. 2004. Relations between stress and work outcomes: The role of felt challenge, job control, and psychological strain. Journal of Vocational Behavior 64(1): 165-181.

Brown, T. A. 2015. Confirmatory factor analysis for applied research. $2^{\text {nd }}$ Edition. New York: Guildford Press.

Browne, M. W. and R. Cudeck. 1993. Alternative ways of assessing model fit. Sage focus editions 154: 136-162.

Byrne, B. M. 2001. Structural equation modeling with AMOS: Basic concepts, applications, and programming. Mahwah, NJ: Lawrence Erlbaum.

Cavanaugh, M. A., W. R. Boswell, M. V. Roehling and J. W. Boudreau. 2000. An empirical examination of self-reported work stress among US managers. Journal of Applied Psychology 85(1): 65-74.

Chamorro-Premuzic, T. and A. Furnham. 2003. Personality predicts academic performance: Evidence from two longitudinal studies on British University students. Journal of Research in Personality 37(4): 319-338.

Christenson, S. L. and M. L. Thurlow. 2004. School dropouts: Prevention considerations, interventions, and challenges. Current Directions in Psychological Science 13(1): 36-39. 
Clark, L. A. and D. Watson. 1995. Constructing validity: Basic issues in objective scale development. Psychological Assessment 7(3): 309-319.

Coates, H. 2005. The value of student engagement for higher education quality assurance. Quality in Higher Education 11(1): 25-36.

Crawford, E. R., J. A. LePine and B. L. Rich. 2010. Linking job demands and resources to employee engagement and burnout: A theoretical extension and meta-analytic test. Journal of Applied Psychology 95(5): 834.

Demerouti, E., A. B. Bakker, F. Nachreiner and W. B. Schaufeli. 2001. The job demands-resources model of burnout. Journal of Applied Psychology 86(3): 499-512.

Di Fabio, A. and L. Busoni. 2007. Fluid intelligence, personality traits and scholastic success: Empirical evidence in a sample of Italian high school students. Personality and Individual Differences 43: 2095-2104.

Downey, L. A., J. Lomas, C. Billings, K. Hansen and C. Stough. 2014. Scholastic success, fluid intelligence, personality, and emotional intelligence. Canadian Journal of School Psychology 29(1): 40-53.

Eagan, K., J. B. Lozano, S. Hurtado and M. H. Case. 2013. The American freshman: National norms. Los Angeles, CA: Higher Education Research Institute, UCLA. http://www.heri.ucla.edu/ monographs/TheAmericanFreshman2013.pdf

Fetvadjiev, V. H., D. Meiring., F. J. van de Vijver, J. A. Nel and C. Hill. 2015. The South African Personality Inventory (SAPI): A culture-informed instrument for the country's main ethnocultural groups. Psychological Assessment 27(3): 827.

Foxcroft, C. and G. Roodt. 2013. An introduction to psychological assessment in the South African context. $4^{\text {th }}$ Edition. Cape Town, South Africa: Oxford University Press Southern Africa.

Fredrickson, B. L. 1998. What good are positive emotions? Review of General Psychology 2(3): 300319.

Gagné, M. and E. L. Deci. 2005. Self-determination theory and work motivation. Journal of Organizational Behavior 26(4): 331-362.

Gatewood, R. D., H. S. Field and M. Barrick. 2011. Human resource selection. $7^{\text {th }}$ Edition. Mason, OH: Cengage Learning.

Govindji, R. and P. A. Linley. 2007. Strengths use, self-concordance and well-being: Implications for strengths coaching and coaching psychologists. International Coaching Psychology Review 2(2): 143-153.

Hill, C., J. A. Nel, F. J. Van de Vijver, D. Meiring, V. H. Valchev, B. G. Adams and G. P. De Bruin. 2013. Developing and testing items for the South African Personality Inventory (SAPI). South African Journal of Industrial Psychology 39(1): 1-13.

Hirschfield, P. J. and J. Gasper. 2011. The relationship between school engagement and delinquency in late childhood and early adolescence. Journal of Youth and Adolescence 40(1): 3-22.

Hoyle, R. H. 1995. Structural equation modelling: Concepts, issues and applications. Thousand Oaks, CA: Sage.

Hu, L. T. and P. M. Bentler. 1999. Cut-off criteria for fit indexes in covariance structure analysis: Conventional criteria versus new alternatives. Structural Equation Modeling 6(1): 1-55.

IBM SPSS. 2013. SPSS 22.0. Chicago, IL: SPSS.

Inceoglu, I. and P. Warr. 2012. Personality and job engagement. Journal of Personnel Psychology 10: $177-181$

Kim, H. J., K. H. Shin and N. Swanger. 2009. Burnout and engagement: A comparative analysis using the Big Five personality dimensions. International Journal of Hospitality Management 28(1): 96104.

Kuh, G. D. 2009. What student affairs professionals need to know about student engagement. Journal 
of College Student Development 50(6): 683-706. doi: 10.1353=csd.0.0099

Langelaan, S., A. B. Bakker, L. J. P. Van Doornen and W. B. Schaufeli. 2006. Burnout and work engagement: Do individual differences make a difference? Personality and Individual Differences 40(3): 521-532.

Li, L. and S. Mao. 2014. Moderating effects of proactive personality on factors influencing work engagement based on the job demands-resources model. Social Behavior and Personality: An International Journal 42(1): 7-15.

Llorens, S., A. B. Bakker, W. B. Schaufeli and M. Salanova. 2006. Testing the robustness of the Job Demands-Resources Model. International Journal of Stress Management 13(3): 378-391.

Louw, G. 2014. Burnout, vigour, big five personality traits and social support in a sample of police officers. South African Journal of Industrial Psychology 40(1): 1-13.

Maurice Kerrigan Africa. 2013. What is achievement orientation and why is it important? http://www.mauricekerrigan.com/blog/what-is-achievement-orientation-and-why-is-it-important/

McCauley, C. D., M. N. Ruderman, P. J. Ohlott and J. E. Morrow. 1994. Assessing the developmental components of managerial jobs. Journal of Applied Psychology 79(4): 544- 560.

McClelland, D. C. 1985. Human motivation. Glenview, IL: Scott, Foresman.

McCrae, R. R. and P. T. Costa. 2003. Personality in adulthood. A five factor theory perspective. The Guildford Press.

Mokgele, K. R. and S. Rothmann. 2014. A structural model of student well-being. South African Journal of Psychology 44(4): 514-527.

Mostert, K., J. Pienaar, C. Gauché and L. T. B. Jackson. 2007. Burnout and engagement in university students: A psychometric analysis of the MBI-SS and UWES-S. South African Journal of Higher Education 21(1): 147-162.

Muthén, L. K. and B. O. Muthén. 2014. Mplus user’s guide. Los Angeles, CA: Muthén and Muthén.

Nel, J. A., V. H. Valchev, S. Rothmann, F. J. Vijver, D. Meiring and G. P. Bruin. 2012. Exploring the personality structure in the 11 languages of South Africa. Journal of Personality 80(4): 915-948.

Nilforooshan, P. and S. Salimi. 2016. Career adaptability as a mediator between personality and career engagement. Journal of Vocational Behavior 94: 1-10.

Ongore, O. 2014. A study of relationship between personality traits and job engagement. ProcediaSocial and Behavioral Sciences 141: 1315-1319.

Ouweneel, E., P. M. LeBlanc and W. B. Schaufeli. 2011. Flourishing students: A longitudinal study on positive emotions, personal resources, and study engagement. The Journal of Positive Psychology 6(2): 142-153.

Parsons, J. and L. Taylor. 2011. Improving student engagement. Current Issues in Education 14(1): 133.

Paterson, H. and J. S. Uys. 2005. Critical issues in psychological test use in the South African workplace. South African Journal of Industrial Psychology 3(3): 12-22.

Paunonen, S. V. and M. C. Ashton. 2001. Big five factors and facets and the prediction of behavior. Journal of Personality and Social Psychology 81(3): 524-39.

Pervin, L. A. and D. Cervone. 2010. Personality: Theory and research. $11^{\text {th }}$ Edition. Hoobo-ken, NJ: John Wiley \& Sons.

Pohl, A. 2013. Reflecting on the importance of student engagement. https://attendengageinvest. wordpress.com/2013/02/06/reflecting-on-the-importance-of-student-engagement/

Poropat, A. E. 2009. A meta-analysis of the Five-factor model of personality and academic performance. Psychological Bulletin 135(2): 322-338.

Potgieter, I. and M. Coetzee. 2013. Employability attributes and personality preferences of postgraduate business management students. South African Journal of Industrial Psychology 39(1): 1-10. 
Rogers, M. E., P. A. Creed and I. Glendon. 2008. The role of personality in adolescent career planning and exploration: A social cognitive perspective. Journal of Vocational Behavior 73(1): 132-142.

Rosander, P. and M. Bäckström. 2014. Personality traits measured at baseline can predict academic performance in upper secondary school three years later. Scandinavian Journal of Psychology 55(6): 611-618.

Rossier, J., G. Zecca, S. D. Stauffer, C. Maggiori and J. P. Dauwalder. 2012. Career Adapt-Abilities Scale in a French-speaking Swiss sample: Psychometric properties and relationships to personality and work engagement. Journal of Vocational Behavior 80(3): 734-743.

Salanova, M. and W. B. Schaufeli. 2008. A cross-national study of work engagement as a mediator between job resources and proactive behaviour. The International Journal of Human Resource Management 19(1): 116-131.

Salanova, M., W. B. Schaufeli, I. Martínez and E. Bresó. 2009. How obstacles and facilitators predict academic performance: The mediating role of study burnout and engagement. Anxiety, Stress \& Coping 26: 1-18.

Salmela-Aro, K. and K. Upadyaya. 2014. School burnout and engagement in the context of demandsresources model. British Journal of Educational Psychology 84(1): 137-151.

Schaufeli, W. B. 2005. Energy and identification as basic dimensions of burnout and engagement. In 12th European Congress on Work and Organizational Psychology. Istanbul, Turkey.

Schaufeli, W. B. and A. B. Bakker. 2004. Job demands, job resources, and their relationship with burnout and engagement: A multi-sample study. Journal of Organizational Behavior 25(3): 293315.

Schaufeli, W. B. and M. Salanova. 2007. Efficacy or inefficacy, that's the question: Burnout and work engagement, and their relationship with efficacy beliefs. Anxiety, Stress \& Coping 20(2): 177196.

Schaufeli, W., M. Salanova, R. Gonzales and A. Bakker. 2002. The measurement of burnout and engagement: A confirmatory analysis. Journal of Happiness Studies 3: 71-92.

Siu, O. L., A. B. Bakker and X. Jiang. 2014. Psychological capital among university students: Relationships with study engagement and intrinsic motivation. Journal of Happiness Studies 15(4): 979-994.

Storm, K. and S. Rothmann. 2003. A psychometric analysis of the Utrecht Work Engagement Scale in the South African police service. South African Journal of Industrial Psychology 29(4): 62-70.

Strauser, D. R., D. O’Sullivan and A. W. Wong. 2012. Work personality, work engagement, and academic effort in a group of college students. Journal of Employment Counseling 49(2): 50-61.

Sulea, C., I. van Beek, P. Sarbescu, D. Virga and W. B. Schaufeli. 2015. Engagement, boredom, and burnout among students: Basic need satisfaction matters more than personality traits. Learning and Individual Differences 42: 132-138. https://doi.org/10.1016/j.lindif.2015.08.018

Uppal, N. and S. K. Mishra. 2014. Moderation effects of personality and organizational support on the relationship between prior job experience and academic performance of management students. Studies in Higher Education 39(6): 1022-1038.

Upadyaya, K. and K. Salmela-Aro. 2013. Development of school engagement in association with academic success and well-being in varying social contexts. European Psychologist 18(2): 136147.

Valchev, V. H., F. J. R. van de Vijver., J. A. Nel, S. Rothmann., D. Meiring and G. P. de Bruin. 2011. Implicit personality conceptions of the Nguni cultural-linguistic groups of South Africa. CrossCultural Research 45(3): 235-266.

Van den Broeck, A., M. Vansteenkiste, H. de Witte and W. Lens. 2008. Explaining the relationships between job characteristics, burnout, and engagement: The role of basic psychological need satisfaction. Work \& Stress 22(3): 277-294.

Van Veldhoven, M., J. de Jonge, S. Broersen, M. Kompier and T. Meijman. 2002. Specific relationships 
between psycho-social job conditions and job-related stress: A three-level analytic approach. Work and Stress 16(3): 207-228.

Van Veldhoven, M., T. F. Meijman, J. P. J. Broersen and R. J. Fortuin. 1997. Handleiding VBBA. Onderzoek naar de believing van psycholosociale arbeidsbelasting en werkstress met behulp van de vragenlijst beleving en beoordeling van de arbeid.

Van Veldhoven, M., T. W. Taris, J. de Jonge and S. Broersen. 2005. The relationship between work characteristics and employee health and well-being: How much complexity do we really need? International Journal of Stress Management 12(1): 3-28.

Wolff, W., R. Brand., F. Baumgarten, J. Lösel and M. Ziegler. 2014. Modeling students’ instrumental (mis-) use of substances to enhance cognitive performance: Neuroenhancement in the light of job demands-resources theory. BioPsychoSocial Medicine 8(1): 1.

Woods, S. A. and J. A. Sofat. 2013. Personality and engagement at work: The mediating role of psychological meaningfulness. Journal of Applied Social Psychology 43(11): 2203-2210.

Xanthopoulou, D., A. B. Bakker, E. Demerouti and W. B. Schaufeli. 2007. The role of personal resources in the job demands-resources model. International Journal of Stress Management 14(2): 121-141.

Yang, H. J. 2004. Factors affecting student burnout and academic achievement in multiple enrolment programs in Taiwan's technical-vocational colleges. International Journal of Educational Development 24(3): 283-301.

Zecca, G., C. Györkös, J. Becker, K. Massoudi, G. P. de Bruin and J. Rossier. 2015. Validation of the French Utrecht Work Engagement Scale and its relationship with personality traits and impulsivity. European Review of Applied Psychology 65(1): 19-28.

Zhang, Y., Y. Gan and H. Cham. 2007. Perfectionism, academic burnout and engagement among Chinese college students: A structural equation modeling analysis. Personality and Individual Differences 43(6): 1529-1540. 